\title{
Editorial: Genetics and Democracy
}

\author{
Maria Hedlund • Niclas Hagen • Ulf Kristoffersson
}

Received: 5 February 2012 / Accepted: 29 February 2012 / Published online: 9 March 2012

(C) Springer-Verlag 2012

The starting point for the network of Genetics and Democracy at Lund University was a discussion among colleagues on how new research results would affect the possibilities of predicting not only genetic variants in relation to disease but also future behaviour. This discussion was launched when the Nuffield Council on Bioethics in 2002 published its report "Genetics and Human Behaviour-the ethical context"; the subject of the report being human behaviour in the "normal range", as opposed to traits that are defined as illnesses or diseases (Nuffield Council on Bioethics 2002). Our initial discussions within the group came to be focused upon behaviour and skills, but we soon widened our scope and tried to look into other aspects of genetic issues in relation to legislation, public health, public understanding of science, as well as public participation in science. It became apparent to us that many of these issues were connected to fundamental values in Western societies and subsequently to the notion of democracy and democratic rule and governance. In 2007, these discussions led to the formation of the network "Genetics and Democracy at Lund University" with members from the fields of clinical genetics, political science, history, ethnology, sociology, and

M. Hedlund

Department of Political Science, Lund University,

Lund, Sweden

N. Hagen

Department of Arts and Cultural Sciences, Ethnology,

Lund University,

Lund, Sweden

\section{U. Kristoffersson $(\bowtie)$}

Department of Clinical Genetics, University and Regional

Laboratories, Region Skane, Lund, and Lund University,

Lund, Sweden

e-mail: ulf.kristoffersson@med.lu.se population genetics applying for grants for a series of lectures on this topic. Since 2007, 14 seminars have been held with distinguished international speakers (Box 1), some of whom have contributed with their presentations as papers to this special issue of the Journal of Community Genetics. We also held an internal half-day seminar presenting ongoing research in the broad field of Genetics and Democracy within Lund University.

Box 1. Lecturers and titles in the seminar series Genetics and Democracy at Lund University 2007-2012

\section{Adam Hedgecoe, Cardiff University}

The Politics of Personalised Medicine-Personal genomics, expectations and promissory science

2. Angus Clarke, Cardiff University

Genes, Knowledge and Autonomy-Whose Knowledge? What Knowledge? When?

3. Herbert Gottweis ${ }^{\mathrm{a}}$, University of Vienna

Operating Biobanks: Towards the Governance of Disappearing Bodies

4. Lene Koch, University of Copenhagen

The Politics of Life - past and present use of genetic knowledge

5. Brian Wynne, Lancaster University

Does genetics have any democratic public(s)? Normative imaginations and risk discourses in modern genetics and genomics

6. Nik Brown, University of York

The metrics of humanness in the UK trans-species embryo debate

7. Martina Cornel ${ }^{\mathrm{a}}$, VU University, Amsterdam

The promises of genomic screening: Building a governance infrastructure

8. Carla van $\mathrm{El}^{\mathrm{a}}$, VU University, Amsterdam

Debating genetic screening: Lessons from the history of genetic screening in the Netherlands

9. Margaret Lock, McGill University, Montreal

Dementia entanglements in a post-genomic Era.

10. John Abraham ${ }^{\mathrm{a}}$, University of Sussex 
The toxico-politics of drugs, genetics and cancer: Transgenic and carcinogenic risk assessment of pharmaceuticals

11. Aad Tibben, Leiden University, Leiden

Predictive genetic testing: What do we know about the impact?

12. Pascal Borry ${ }^{\mathrm{a}}$, K.U. Leuven, Leuven

Genes and the Internet: Possibility, threat or actual change?

13. Jorge Sequerios ${ }^{\mathrm{a}}$, University of Porto, Porto

Definitions of genetic testing in European legal documents

14. Sirpa Soini ${ }^{\text {a }}$, University of Helsinki, Helsinki

Genetic testing legislation in the Western Europe - a fluctuating regulatory target

Seminars 11 and 12 were held in collaboration with the Learning and Media Technology Studio, University of Gothenburg (www.letstudio.gu.se)

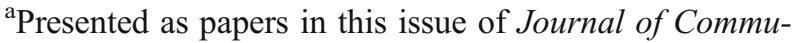
nity Genetics

It was our goal to explore how legislators and social welfare and health care systems are coping with advances in genetic science and its use for the good of citizens. Democratic considerations pertained not only to political decision making and accountability but also to the possibilities of the inclusion of concerned parties for a plurality of views to be considered, as well as to the outcomes of those processes. Our series of lectures provides some snapshots from different areas and gives an overview of the broad field of scientific advances in genetics, if by no means a full one.

We, the guest editors of this issue of the Journal of Community Genetics, are thankful to the Editor-in-chief and the Publisher for allowing us to introduce some of the presentations from this seminar series.

\section{The outline of the special issue}

In their paper, "Power, expertise and the limits of representative democracy: genetics as scientific progress or political legitimating in carcinogenic risk assessment of pharmaceuticals?" John Abraham and Rachel Bollinger investigate the regulative framework for assessing the carcinogenic effects of new pharmaceuticals and the role of genetics in this risk assessment. They conclude that the techno-regulatory standards for carcinogenic risk assessment have come to be loosened in ways that are presented as scientific progress resulting from new genetics, but for which there is little evidence of progress in public health protection (Abraham and Ballinger 2012). Their paper confronts the issue of who has control of the agenda and, ultimately, of effective participation by the public in a representative democracy in affairs that are of concern for the public.

Public participation, enlightened understanding and inclusiveness form an underlying basis for the paper "Genetic screening and democracy: lessons from debating genetic screening criteria in the Netherlands" by Carla van El, Toine Peters and Martina Cornel, who study the public debates on genetics in conjunction with the new possibilities and new situation offered by genetic screening (Van El et al. 2012).

In another paper on genetic screening, "The promises of genomic screening: building a governance infrastructure" by Martina Cornel, Carla van El and Wybo Dundorp, the authors argue for the need of an infrastructure in order to facilitate a greater concordance between various actors, as well as to achieve a transparent control of the agenda setting in conjunction with the development and implementation of screening programs (Cornel et al. 2012).

Participation and inclusiveness are also present in Herbert Gottweis' and Georg Lauss' article 'Biobank governance: heterogeneous modes of ordering and democratization" in which they present and utilize an analytical model in order to study and compare the governance of biobanks. The authors further discuss attempts to develop governance structures that permit participation of those concerned, and they conclude that a facilitation of an integration of more or less interrelated actors within the context of biobanking should not be equated with democratization per se, but can nevertheless be regarded as an important step towards a more pluralistic and inclusive style of policy making (Gottweis and Lauss 2012).

In the article "Is there a doctor in the house? The presence of physicians in the direct-to-consumer genetic testing context" Heidi Howard and Pascal Borry (Howard and Borry 2012) investigate the involvement of health care professionals in the business models adopted by companies offering genetic testing through the Internet (Direct-to-Consumer Genetic Testing). The emergence of Direct-toConsumer Genetic Testing might undermine, or even short-cut, the influence of the medical community and the decision making through democratic channels on the use of new applications within genetics and genomics as commercialization of genetic tests is based upon a consumer/marketbased logic rather than public decision making.

Jorge Sequerios presents his contribution on genetic definitions in European legal documents and international recommendations, guidelines and reports in two co-authored papers (Varga et al. 2012; Sequeiros et al. 2012).

With regard to legal documents, genetic testing is more often defined in non-binding legal documents than in binding ones. Definitions are core elements of legal documents, and their accuracy and harmonization (particularly within a particular legal field) are critical to the interpretation of the document, if their implementation is not to be compromised. In the paper by Varga et al. (2012), the authors conclude that they have gathered evidence for the need of a clear differentiation between (a) "clinical genetics testing", (b) "genetics laboratory-based genetic testing" and (c) "genetic information". 
With regard to international recommendations, guidelines and reports, Sequeiros et al. (2012) concluded that a common consensus definition of genetic testing does not exist. The authors argue that a clear set of precise definitions may help create a common language among geneticists and other health professionals, and that a clear context-dependent, operative definition should always be given.

Sirpa Soini's presentation covers genetic testing legislation. Five countries have enacted genetic-specific laws, and three have comprehensive provisions pertaining to genetic testing in their biomedical legislation. Central provisions cover the informed consent, autonomy and integrity of the person tested, further uses of tests results, and quality requirements of the personnel and facilities involved. The notion of genetic exceptionalism was characteristic to the normative reactions in the legal acts, but Soini (2012) questions how justified this is.

Acknowledgments Research grants making this series of lectures possible have been received from: the Erik-Philip Sörensen Foundation for Research in Medicine and the Humanities, the Karin and Hjalmar Tornblad Foundation, the Fahlbeck Foundation and the Nilsson-Ehle Foundations of the Royal Physiographic Society in Lund.

All contributors to this special issue are acknowledged for their contributions making this special volume possible. Seminars 11 and 12 were held in collaboration with the Learning and Media Technology Studio (LETStudio), University of Gothenburg.

\section{References}

Abraham J, Ballinger R (2012) Power, expertise and the limits of representative democracy: genetics as scientific progress or political legitimation in carcinogenic risk assessment of pharmaceuticals? J Community Genet. doi:10.1007/s12687-011-0060-2

Cornel MC, van Carla G, El CG, Dondorp WJ (2012) The promises of genomic screening: 1 building a governance infrastructure. $\mathrm{J}$ Community Genet. doi:10.1007/s12687-011-0056-y

Gottweis H, Lauss G (2012) Biobank governance: heterogeneous modes of ordering and democratization. J Community Genet. doi:10.1007/s12687-011-0070-0

Howard H, Borry P (2012) Is there a doctor in the house? The presence of physicians in the direct-to-consumer genetic testing context. J Community Genet. doi:10.1007/s12687-011-0062-0

Nuffield Council on Bioethics (2002) Genetics and human behaviourthe ethical context. http://www.nuffieldbioethics.org/sites/default/ files/Genetics\%20and\%20human\%20behaviour.pdf

Sequeiros J, PanequeM GB, Rantanen E, Javaher P, Nippert I, Schmidtke J, Kääriäainen H, Kristoffersson U, Cassiman J-J (2012) The wide variation of definitions of genetic testing in international recommendations, guidelines and reports. J Community Genet. doi:10.1007/s12687-012-0084-2

Soini S (2012) Genetic testing legislation in the Western Europe-a fluctuating regulatory target. J Community Genet. doi:10.1007/ s12687-012-0078-0

Van El CG, Pieters T, Cornel M (2012) Genetic screening and democracy: lessons from debating genetic screening criteria in the Netherlands. J Community Genet. doi:10.1007/s12687-011-0063-Z

Varga O, Soini S, Kääriäinen H, Cassiman J-J, Nippert I, Rogowski W, Nys H, Kristoffersson U, Schmidtke J, Sequeiros J (2012) Definitions of genetic testing in European legal documents. J Community Genet. doi:10.1007/s12687-012-0077-1 